\title{
FONTES SOBRE A HISTÓRIA DA MÚSICA EM DESTERRO ${ }^{1}$
}

\author{
Marcos Tadeu Holler²
}

\begin{abstract}
RESUMO: Este projeto tem como objetivo a inserção do Estado de Santa Catarina no cenário da musicologia histórica brasileira, por meio de um levantamento de fontes sobre a prática e o ensino da música na Ilha de Santa Catarina e na Vila de Nsa. Sra. do Desterro (atual Florianópolis) nos sécs. XVIII e XIX. Nesta primeira etapa foi feito um levantamento de informações sobre música em periódicos desde 1831, data da primeira publicação, até o final do Império, em 1889.
\end{abstract}

PALAVRAS-CHAVE: História da música no Brasil; História da imprensa; História de Santa Catarina; Pesquisa documental

\section{A musicologia histórica no Brasil e em Santa Catarina}

A musicologia histórica ainda é uma área recente no Brasil, se comparado com outros países, tendo se iniciado de forma sistemática somente com os trabalhos de Kurt Lange nos anos 40. Nas décadas que seguiram a pesquisa musicológica manteve-se focada em alguns centros, como Minas Gerais, Rio de Janeiro e São Paulo; em seguida vieram os trabalhos sobre estados do Nordeste e Norte. Somente muito recentemente os estados do sul se viram incluídos nesse panorama, e o Estado de Santa Catarina ainda tem muitas fontes sobre sua memória musical a serem desveladas. Em mesa redonda realizada no I Simpósio Latino-Americano de Musicologia, de 1998, a musicóloga Maria Elizabeth Lucas já apontava para a necessidade da inclusão dos estados do Sul no cenário da musicologia histórica brasileira:

Quero [...] chamar a atenção para o fato de que não são de interesse musicológico apenas aquelas regiões de alta visibilidade históricodocumental. As chamadas regiões periféricas da sociedade colonial, praticamente ausentes da historiografia musical brasileira, a exemplo

\footnotetext{
${ }^{1}$ Projeto de Pesquisa: A música na imprensa em Desterro no séc. XIX, Centro de Artes da Universidade do Estado de Santa Catarina (UDESC).

${ }^{2}$ Doutor em Musicologia pela Universidade Estadual de Campinas (UNICAMP), professor do Departamento de Música da UDESC. E-mail: mholler@udesc.br.
} 
da região sulina, representam elos importantes na compreensão [das mudanças na cultura musical]. (LUCAS, 1998, p.73)

Além de pesquisas que envolvam os estado do Sul e o conhecimento de seus acervos, Lucas menciona ainda a necessidade de uma maior integração e intercâmbio de informações entre esses estados.

Em palestra na Universidade Federal da Bahia, em 2004, Paulo Castagna discorreu sobre as necessidades da musicologia no Brasil atual de sistematização de fontes e catalogação de acervos. Segundo o autor,

ainda resta muito trabalho a ser feito no que se refere à catalogação de acervos, edição de obras, organização e sistematização de fontes, o que impõe à nova musicologia a responsabilidade de desenvolver trabalhos sistemáticos e, ao mesmo tempo reflexivos. (CASTAGNA, 2004a)

Além do conhecimento dos acervos, Castagna menciona ainda a necessidade de metodologias adequadas à realidade da musicologia brasileira:

A nova musicologia, no país, terá que se preocupar com o aspecto crítico e reflexivo, mas também deverá investir um grande esforço na sistematização das fontes, e desta vez com maior rapidez e consciência metodológica. Como isso não pode ser feito a partir de um pequeno círculo, a musicologia brasileira se vê forçada a uma urgente ampliação do número de pesquisadores e a uma rápida atualização metodológica. Tudo isso, porém, somente reforça o fato de que a musicologia brasileira já começou a se transformar, não se contentando mais com os antigos modelos europeus e nem mesmo com os antigos procedimentos usados no estudo da prática e produção musical brasileira até meados da década de 1990. (CASTAGNA, 2004b)

O objetivo deste projeto de pesquisa é o levantamento de fontes sobre a prática e o ensino da música na Ilha de Santa Catarina e na Vila de Nsa. Sra. do Desterro (atual Florianópolis) nos sécs. XVIII e XIX, possibilitando um mapeamento de seus acervos documentais e sua utilização para outras pesquisas na área. Nesta primeira etapa foi feito um levantamento de informações sobre música em periódicos desde 1831, data da primeira publicação, até o final do Império, em 1889. 
Como fundamento para a pesquisa, foram consultadas as obras Nas tramas entre $o$ público e o privado, de Joana Maria Pedro (1995), que apresenta em seus anexos algumas tabelas com dados das publicações de jornais de 1831 até 1892, e a dissertação de mestrado de Adélia dos Santos Silveira, Catálogo analítico descritivo dos jornais do Desterro: 18501984 (1981), que também apresenta algumas descrições dos jornais do séc. XIX.

Os textos sobre história da música em Santa Catarina são raros. As obras A música em Santa Catarina no século XIX de Oswaldo Rodrigues Cabral e A história da música, de Hélio Teixeira da Rosa, capítulo do livro História sócio-cultural de Florianópolis, coordenado por Osvaldo Ferreira de Melo, ambas de 1951, apresentam alguns dados, porém sem consistência musicológica. Em Nossa Senhora do Desterro: memória (1972), Oswaldo Rodrigues Cabral dedica um capítulo à história das artes plásticas e da música em Florianópolis desde o séc. XVII; segundo o autor, a música estava mais em evidência que as artes plásticas, como mostra o título do capítulo: Em matéria de artes plásticas e rítmicas, houve mais notas do que tintas. Cabral dedica outro capítulo ao teatro, também apresentando algumas informações sobre música. Assim como as obras anteriores, o texto de Oswaldo Cabral é relevante pelas suas referências a algumas das fontes, porém não apresenta conclusões consideráveis.

Como textos mais recentes podem-se mencionar o trabalho de conclusão de curso da acadêmica Ana Ribamar Braga, Fontes sobre a história da música em Santa Catarina (2000), que foi o ponto de partida para essa pesquisa, e $A$ vitrola nostálgica de Marcelo Téo (2007) que aborda aspectos da música em Santa Catarina a partir de uma perspectiva histórica mais coerente do ponto de vista metodológico, e discorre também sobre algumas fontes.

\section{A Ilha de Santa Catarina e a Vila de Nsa. Sra. do Desterro}

No início do séc. XVI a Ilha de Santa Catarina era conhecida pelos navegadores portugueses como a Ilha dos Patos, e somente recebeu a denominação atual em 1516, com a passagem do navegador italiano Sebastião Caboto, a serviço da Espanha. O primeiro

povoamento da Ilha e fundação do povoado de Nsa. Sra. do Desterro foi realizado por Francisco Dias Velho em 1678. Em 1689 o povoado, já com cerca de 400 habitantes, foi 
atacado por piratas, e a população abandonou o local. O povoamento definitivo iniciou-se em 1700, com alguns casais vindos de Lisboa; em 1726 o povoado passou à categoria de vila, e em 1738 passou a ser a capital da Capitania de Santa Catarina. Em 1748 chegaram as primeiras famílias de imigrantes açorianos, que em 1756 já totalizavam um número de 6.000 indivíduos. No séc. XIX o crescimento de Nsa. Sra. do Desterro foi constante, e em 1894 passou a se chamar Florianópolis, homenagem ao Marechal Floriano Peixoto, Presidente na época (PIAZZA, 2003). Devido ao fato de o período do levantamento que fundamenta este trabalho ser anterior à mudança do nome, no texto será mantido o nome Desterro.

\section{Fontes documentais sobre a música em Desterro}

As referências mais antigas a uma prática musical em Desterro são os relatos da Companhia de Jesus, nos quais se encontram informações referentes às passagens dos padres jesuítas pela província no séc. XVII e ao estabelecimento de missões e do Colégio de Desterro no séc. XVIII; vários desses documentos encontram-se transcritos na tese de doutorado Uma história de cantares de Sion na terra dos brasis: a música na atuação dos jesuítas na América Portuguesa (2006), do autor deste trabalho. A Ânua da Província do Brasil de 1748 e 1749 (An.FrSilv, 1750, f. 430) menciona o Terço do Rosário cantado todos os dias no Colégio da Ilha de Santa Catarina, e a Ânua da Província do Brasil de 1754 (An.InPas, 1755, f. 447v) descreve o canto do Terço pelos filhos dos colonos açorianos todos os sábados.

Documentos das irmandades e paróquias também constam entre as fontes para a descrição de eventos musicais em Desterro no séc. XVIII. Como era uma prática comum entre os historiadores no século passado, muitos desses documentos encontram-se publicados. Um exemplo é a obra Memorial Histórico da Irmandade do Senhor Jesus dos Passos (1997), organizada por Nereu do Vale Pereira. A receita do exercício da Irmandade de 1767 a 1768, publicada na obra, mostra 9.000 réis pagos a "José de Almeida Moura pela música para a procissão dos Passos” (p. 117). Um artigo n'O Argos de 22 de junho de 1861 menciona o mesmo José de Almeida Moura como “o primeiro que em Santa Catarina ensinou música". 
Uma outra importante fonte de informações sobre esse período são os relatos de viajantes que passaram pela Ilha nos sécs. XVIII e XIX. Até o momento foram encontrados 16 relatos publicados, a maioria em transcrições ou traduções, e alguns deles em suas publicações originais. Os próprios relatos descrevem os focos de atividade musical na Ilha no final do séc. XVIII e início do séc. XIX: os militares, presentes na Ilha devido à proximidade com os territórios espanhóis, que contribuiriam para a prática musical em Desterro com as bandas; os portugueses vindos de Lisboa e habitantes da Vila, que segundo os relatos mostravam hábitos completamente europeus, e os açorianos, de costumes mais simples e que consistiam as comunidades de pescadores estabelecidas em regiões da Ilha afastadas do centro urbano; os negros, tanto escravos quanto libertos, que também segundo os relatos eram uma parcela considerável da população; e por fim os índios, que eram presentes na Ilha porém não se deixavam ser vistos com facilidade.

A leitura desses textos deve ser realizada de forma crítica, pois deve-se levar em conta que os relatos dos viajantes eram escritos com a finalidade de uma posterior publicação na Europa, e por esse motivo o objeto de descrição era geralmente o estranho, curioso, ridículo ou grotesco aos olhos e ouvidos europeus, e essas características não somente determinam o objeto ou evento a ser descrito, mas também a forma de descrição. Isso é evidente no relato do russo Urey Lisiansky, capitão do navio Neva, que esteve em Santa Catarina em 1803:

Os costumes dos senhores, diferindo pouco dos usados pelos católicos da Europa, quase não atraíam minha atenção. O que não acontecia com relação aos negros que, estando divididos em grupos, de acordo com seus aspectos, produziam em mim uma grande diversão, com suas esquisitas danças típicas. (LISIANSKY apud HARO, p. 154)

Alguns dos colonizadores, sobretudo dos imigrantes açorianos, são vistos com uma certa condescendência pelos viajantes, ao contrário do que ocorre com as práticas dos negros, descritas por adjetivos como "estranho", "selvagem" ou "horrível", e termos como "ruídos" e "barulhos".

Entre os relatos pode-se mencionar Histoire d'un Voyage aux isles Malouines, fait en $1763 \& 1764$ do naturalista francês Antoine Joseph Pernetty (1729-1811), que passou pela 
Ilha de Santa Catarina em 1763. Já nessa época a Ilha agradava aos viajantes que passavam por ela; segundo Pernetty, "a ilha se tornaria numa morada excelente, se fossem tomadas providências para desbravá-la” (p. 153). Pernetty (1770, p. 140) relata que, após um jantar na casa do Governador, "uma dúzia de oficiais da guarnição entraram, e nos regalaram um pequeno concerto de música instrumental. Eles tinham quase todas as peças dos melhores músicos franceses, e pareciam executá-las como Corelli ou Gaviniez". 3

O relato com informações mais extensas e detalhadas sobre música por exemplo o médico e naturalista Barão Georg Heinrich von Langsdorff, que esteve na Ilha de Santa Catarina entre 1803 e 1804, e em 1812 publicou um relato de suas viagens com a expedição russa, da qual fazia parte. Langsdorff descreve os portugueses que habitavam a Ilha como "atenciosos, cordiais e expansivos", e relata que

à noite, reúnem-se em pequenos grupos familiares onde, segundo o costume português, dançam, riem, fazem gracejos, cantam e brincam. Os instrumentos mais comuns são a viola e o saltério ${ }^{4}$. A música é expressiva, agradável e contagiante, as canções têm o conteúdo de costume e falam geralmente de belas jovens, de nostalgia e do amor e sofrimentos do coração. (LANGSDORFF, 1818, p. 163).

Essa referência é a única encontrada até o momento sobre presença do saltério na Ilha, porém esse era um instrumento comum entre os portugueses nos sécs. XVIII e XIX e outros documentos descrevem sua presença no Brasil, como por exemplo o álbum com cifras de saltério encontrado em Paranaguá, e descrito por Budasz (2002).

Langsdorff esteve também em uma fazenda no interior do continente, e lá as filhas do proprietário cantaram algumas canções a seu pedido; como ilustração para essas canções Langsdorff transcreve na publicação uma partitura com o título de "ária brasileira" ou "modinha" que, até o momento, é a partitura mais antiga de uma modinha datada e indubitavelmente coletada no Brasil.

\section{Jornais}

\footnotetext{
${ }^{3}$ Todas as traduções foram realizadas pelo autor deste trabalho.

${ }^{4} \mathrm{Na}$ versão consultada, em tradução para o holandês, os termos originais são "de guitar em het hakkebord".
} 
Na etapa inicial desta pesquisa foram consultados os jornais publicados em Desterro entre 1831, data do primeiro periódico em Santa Catarina, e 1889, que marca a transição do Império para a República. O principal acervo consultado foi o da Biblioteca Pública do Estado de Santa Catarina, que possui a maioria dos jornais do séc. XIX. Cabe observar que foi relevante a utilização do acervo da Biblioteca Pública do Estado de Santa Catarina para uma pesquisa acadêmica, visto que o Governo do Estado acenou para a possibilidade de municipalização ou, o que é mais drástico, privatização de seu espaço. Por meio da pesquisa, o espaço e seu acervo tornaram-se um elemento vivo e com um importante potencial de retorno à comunidade.

Os jornais publicados a partir de 1850 encontram-se disponíveis na versão impressa, e podem ser consultados a partir de um catálogo disponível na Biblioteca. Os jornais anteriores a essa data estão disponíveis somente em microfilme.

O primeiro jornal publicado em Desterro foi $O$ Catarinense, de 1831, depois seguido por O Brasil, (1831 a 1832); O Expositor, (1832 a 1833); Benfazejo, (1836 a 1840); Mercantil, (1845 a 1847); Relator Catarinense, (1845); O Progresso Catarinense, (1849); O 3 Conciliador Catarinense, (1849 a 1851). Os principais periódicos publicados a partir de 1850 são os seguintes: O Novo Íris, (1850 a 1852); O Correio Catarinense, (1852 a 1854); A Revelação, (1852 a 1853); O Conservador, (1852 a 1855); O mensageiro, (1855 a 1857); O Argos da Província de Santa Catarina, (1856 a 1862); Bota Fogo, (1858); O Cruzeiro do Sul, (1858 a 1860); O Catarinense, (1860 a 1861); O Chaveco, (1860 a 1861); O Correio Oficial, (1860 a 1861); O Cruzeiro, (1860); O Progressista, (1860 a 1861); O Mercador, (1861); O Mercantil, (1861 a 1869); A Quinzena, (1861 a 1862); Pacajá, (1862); O Despertador, (1863 a 1885); Periódico da Semana, (1864 a 1865); O Beija-Flor (1867 a 1868); A Regeneração (1868 a 1889); O Conservador (1871 a 1889); A Verdade (1880 a 1894); Matraca (1881 a 1888); Tribuna Popular (1885 a 1892); O Crepúsculo (1887 a 1889); O Mosquito (1888 a 1889); República (1889 a 1894) e O Estado (1892 a 1894).

Um dos temas enfocados a partir do levantamento de informações nos jornais foi a atuação de bandas em Desterro no séc. XIX. As bandas tinham uma participação extremamente ativa em diversos aspectos da sociedade urbana nesse período, o que pôde 
ser verificado por meio dos artigos encontrados. As primeiras bandas surgiram em Desterro no âmbito militar, e aos poucos as sociedades civis passaram a ocupar o espaço deixado pelos grupos militares. Foram encontradas referências a cerca de 20 bandas e sociedades musicais (termo pelo qual esses grupos também eram conhecidos). Algumas bandas são mencionadas com bastante frequiência e por um longo período de tempo, como a Sociedade Musical Trajano, que existiu por pelo menos 10 anos. A sociedade Amor à Arte, fundada em 1875, segundo $O$ Conservador de 9 de outubro do mesmo ano, ainda estava ativa até o momento da realização deste artigo.

Os termos utilizados nos artigos para as bandas geralmente são bastante elogiosos, e a participação de jovens nesses grupos é sempre louvada. Uma comunicação n'O Despertador de 9 de março de 1875 descreve a inauguração de uma fábrica de sabão e velas com a participação da banda Trajano, que era "composta por jovens distintos e uniformizados"; outro artigo no mesmo jornal descreve a participação de jovens em um desses grupos:

O Club Euterpe Quatro de Março, composto de moços inteligentes e honestos, vai prosperando e merecendo aplausos. Esta sociedade exibiu-se na Festa da Imagem do Senhor dos Passos, ocupando o coro da igreja, desempenhando perfeitamente o Cântico Doloroso do Senhor. Na procissão entoou o salmo em todos os Passos onde a Imagem parava. Esta sociedade, além de ser um delicioso passatempo, é uma escola de belas artes. (O DESPERTADOR, 19 de março de 1872)

A banda Trajano era modelo para outros grupos que surgiam: um artigo de julho de 1875 descreve a criação da sociedade Philarmonica Commercial, que era "composta por jovens comerciantes, amantes da arte da música, que resolveram fazer uma banda de música como a Trajanos" (O DESPERTADOR, 24 de julho de 1875).

Além das bandas, outro tema enfocado foi a música feita nos teatros no final no séc. XIX, particularmente no Teatro Santa Isabel, atual Teatro Álvaro de Carvalho (TAC), o que permite entrever o papel desempenhado pelos teatros na vida social de Desterro da época. Até meados do século a principal casa de espetáculos era o teatro D. Pedro; em 1875 foi fundado o Teatro Santa Isabel, e nas últimas décadas do séc. XIX a programação foi intensa. Os jornais trazem anúncios de espetáculos e transcrevem programas de concertos,o 
que possibilita o conhecimento do repertório comum da época e mostra o gosto pela ópera italiana, embora surjam algumas peças francesas e de repertório não-operístico. No período ainda não se encontrava nos jornais a figura do crítico profissional, porém era dado espaço para que os leitores se manifestassem para a crítica ou elogio dos espetáculos.

Além das apresentações de companhias externas, os teatros eram espaço para os grupos de compositores locais. Um compositor mencionado com grande freqüência é José Brasilício de Souza, que teve óperas suas apresentadas nos teatros e regeu grupos musicais, entre outros.

\section{Considerações finais}

Até as últimas décadas a pesquisa musicológica no Brasil esteve voltada para a produção nos grandes centros, e praticamente ignorou as práticas em regiões periféricas. Trabalhos recentes envolvendo essas periferias têm demonstrado várias possibilidades de estudo, e o levantamento de informações mostram que ainda existem grandes lacunas na historiografia da música no Brasil.

Neste texto foram apresentadas algumas fontes que podem fornecer informações sobre a prática e o ensino da música em Desterro nos sécs. XVIII e XIX. A leitura dessas informações deve ser realizada de forma crítica, levando-se em conta que o intuito na produção desses documentos nem sempre era o de uma descrição precisa e imparcial.

Como uma etapa posterior à consulta aos documentos impressos, pretende-se partir para a consulta aos acervos de documentos manuscritos, como o das antigas paróquias de Florianópolis, que é dificultada pela falta de sistematização e pela restrição à consulta de externos.

Cabe ressaltar que os dados apresentados aqui referem-se à etapa inicial da

pesquisa, que corresponde ao levantamento de dados, e que em desenvolvimentos posteriores esse levantamento levará à reflexão e à análise crítica das informações encontradas. 


\section{REFERÊNCIAS BIBLIOGRÁFICAS}

BRAGA, Ana Ribamar. Levantamento de aspectos da cultura musical em Desterro nos séculos XVIII e XIX. Monografia de conclusão de curso. Florianópolis: Universidade do Estado de Santa Catarina (UDESC), Centro de Artes, 2000.

BUDASZ, Rogério. Cifras de música para saltério: Música de salão em Paranaguá e Morretes no início do século XIX. Curitiba: Editora da Universidade Federal do Paraná, 2002.

CABRAL, Oswaldo Rodrigues. A música em Santa Catarina no século XIX. Florianópolis: [s.e.], 1951.

CABRAL, Oswaldo Rodrigues. Nossa Senhora do Desterro: memória. Florianópolis: Imprensa da Universidade Federal do Estado de Santa Catarina, 1972.

CASTAGNA, Paulo. A musicologia enquanto método científico. Salvador, 2004b. Palestra proferida na Universidade Federal da Bahia em novembro de 2004.

CASTAGNA, Paulo. Avanços e perspectivas na musicologia histórica brasileira. Salvador, 2004a. Palestra proferida na Universidade Federal da Bahia em novembro de 2004.

CATÁLOGO de Jornais Catarinenses: 1850-1989. Florianópolis: s.e., 1990.

HARO, Martim Afonso Palma de Haro. Ilha de Santa Catarina - Relato de viajantes estrangeiros nos séculos XVIII e XIX. Florianópolis: Editora Lunardelli, 1996.

HOLLER, Marcos Tadeu. Uma história de cantares de Sion na terra dos brasis: a música na atuação dos jesuítas na América Portuguesa. Tese de doutorado. Campinas:

Universidade Estadual de Campinas (UNICAMP), Instituto de Artes, 2006. 2 vols.

LANGSDORFF, Georg Heinrich von (Barão). Reis rondom de Wereld in de Jaren 1803 tot 1807. Tradução de Bemerkungen auf einer Reise um die Welt in den Jahren 1803 bis 1807 von G. H. von Langsdorff, Kaiserlich-Russischen Hofrath, Ritter des St. Annen-Ordens zweiter Klasse, Mitglied mehrerer Akademien und gelehrten Gesellschaften. Amsterdam: J. C. van Kesteren, 1818.

LUCAS, Maria Elizabeth. Perspectivas da pesquisa musicológica na América Latina: o caso brasileiro. In: I SIMPÓSIO DE MUSICOLOGIA, Curitiba, 1998. Anais. Curitiba: Fundação Cultura de Curitiba. 1998. p. 69-74.

PEDRO, Maria Joana. Nas tramas entre o público e o privado: a imprensa de Desterro, 1831- 1889. Florianópolis: Editora da UFSC, 1995.

PEREIRA, Nereu do Vale (org.). Memorial Histórico da Irmandade do Senhor Jesus dos passos. Florianópolis: Ministério da Cultura, 1997. 2 vols. 
PERNETTY, Antoine Joseph. Histoire d'un Voyage aux isles Malouines, fait en 1763 \& 1764, avec des Observations sur le detroit de Magellan, et sur les Patagons, par Dom Pernetty, abbé de l'Abbaye de Burgel, Membre de l'Academie Royale des Sciences \& Belles Lettres de Prusse, Associé correspondant de celle de Florence \& Bibliothécaire de Sa Majesté le Roi de Prusse. Paris: chez Saillant \& Nyon, 1770.

PIAZZA, Walter Fernando. Santa Catarina: História da Gente. Florianópolis: Lunardelli, 2003.

ROSA, Hélio Teixeira da. A História da Música. In: MELO, Osvaldo Ferreira de (coord). História sócio-cultural de Florianópolis. Florianópolis: Lunardelli, 1991. Pp. 155-175.

SILVEIRA, Adélia dos Santos. Catálogo analítico descritivo dos jornais do Desterro: 1850- 1984 (o jornal como fonte histórica). Dissertação de mestrado. Florianópolis, Universidade Federal de Santa Catarina, Centro de Filosofia e Ciências Humanas, 1981.

TÉO, Marcelo. A Vitrola Nostálgica: música e constituição cultural em Florianópolis (décadas de 1930 e 1940). Florianópolis: Letras Contemporâneas Oficina Editorial Ltda, 2007.

\section{Documentos manuscritos}

An.FrSilv, 1750. Ânua da Província do Brasil de 1748 e 1749. Padre Francisco da Silveira. Colégio da Bahia, 15 de janeiro de 1750. Fonte: original no ARSI, Bras 10 II, doc. LXVI, ff. 429-430v. Transcrito em HOLLER, 2006, vol. 2, p. 306.

An.InPas, 1755. Ânua da Província do Brasil de 1754. Padre Inácio de Passos. Colégio da Bahia, 16 de janeiro de 1755. Fonte: original no ARSI, Bras 10 II, doc. LXIX, ff. 445-449. Transcrito em HOLLER, 2006, vol. 2, p. 304.

\section{Jornais}

O Argos da Província de Santa Catarina. Desterro, 1856-1862. Semanal.

O Conservador, Desterro, 1871-1883. Bissemanal.

O Despertador. Desterro, 1863-1885. Bissemanal. 